\title{
USING PADRISEUP AS A COLLABORATIVE WRITING TOOL IN HIGHER EDUCATION EFL CLASSES
}

\author{
Beyza Öz Dal, Dilek Güler, Istanbul University, Ezgi Tufan, Mentora Education Group, \\ Ayşegül Liman Kaban, Bahçeşehir University, Turkey
}

\section{Abstract}

Due to the sudden outbreak of COVID-19, there has been a rapid transformation of the learning and teaching environment from face-to-face to fully online classes. Students being at home in isolated home environments challenged the language learning process profoundly which forced teachers to update and adjust their instructional strategies and activities by including collaborative learning elements. Implementing novel technologies with OCL approach might act as a considerably efficient factor if learner characteristics and the educational setting are taken into consideration seriously. Therefore, the purpose of the study is to explore an online collaborative writing tool and students' opinions towards it. The participants of the study consist of 30 students studying at a preparatory school at a state university in Istanbul. To this aim, both quantitative and qualitative methods have been benefited. According to the quantitative data, the calculated mean scores of the items revealed that the majority of students found the experience of OCW positive. As for the qualitative data, the content analysis showed that the majority of the students reported the benefits of interaction and social learning taking place in collaborative learning, and there were also some disadvantages mentioned by the participants such as disagreements, social loafing, and personality-related problems.

\section{Introduction}

The whole system of education including primary, secondary, high schools and universities have been seriously challenged during the lockdown period of the COVID-19 pandemic across the world. In fact, the circumstances all the stakeholders in education are in are unique and it is more accurate to call it crisis learning, unlike normal digital learning (Pace et al., 2020). Therefore, there has emerged a greater need for academic institutions to alter their curriculum and reconsider the utilization of novel instructional methods and strategies (Toquero, 2020). Pace et al., (2020) further state that while planning the instructional activities, it is crucial to strive for high student engagement and participation 
which match the lesson objectives, and the key point is providing the learners with a "choice". Messer (2020) explains that "Young adolescents thrive when given opportunities to pursue their passions and take ownership of their learning. Significant academic and social growth happen in a middle school classroom where students have a voice about their learning" (p.4). Consequently, online collaboration tools prove to be powerful tools that provide the learners choice and voice, which eventually promotes overall learning and participation online.

\section{Online Collaborative Learning}

According to the online dictionary of Lexico (n.d) collaboration is defined as "the action of working with someone to produce something". Ananiadou and Claro (2009) posit that collaboration is regarded as one of the $21^{\text {st }}$ century competencies needed to cope with the fast-changing nature of the era. Collaboration is an essential component in every aspect of life, including education. Dillenbourg (1999) define collaborative learning "is that it is a situation in which two or more people learn or attempt to learn something together" (p.1). According to Johnson and Johnson (1991) Collaborative Learning (CL) is "the instructional use of small groups so that students work together to maximize their own and each other's learning”. The key components of CL encompass positive interdependence, face-to-face interaction, individual accountability, and the interpersonal and small group skills (Johnson \& Johnson, 1991). CL gets its roots from Vygotsky's (1978) concept of Zone of Proximal Development which posits the idea that learning through collaboration and interaction enables the person to reach a higher level of performance and knowledge compared to learning individually and without support. Along with the technological advances, especially with the invention of the World Wide Web, online education has gained momentum, and in the $21^{\text {st }}$ century both teachers and students around the globe use and readjust networked collaborative learning (Harasim, 2000). Collaborativism aka Online Collaborative Learning Theory (OCL) can be defined as a type of learning where learners are motivated and assisted to work with each other to learn and produce knowledge; it is comprised of a process having three phases as "Idea Generating", "Idea Organizing" and "Intellectual Convergence" (Harasim, 2017). In OCL environments, the instructor has a crucial role as the person who is responsible for students' engagement in the particular grammar point or vocabulary along with other activities related to constructing discipline, and the learner is supposed to get involved in all three phases of collaborativist pedagogy to learn and find a solution to a problem (Harasim, 2017). Thanks to the authentic tasks that necessitate collaborative problem solving and profound involvement, learners will show improvement in terms of communication and problemsolving skills (Reeves et al., 2004). 


\section{Online collaborative writing and the use of online tools}

Particularly Web 2.0 tools such as Google Docs, Wikis and blogs have attracted significant attention from researchers in the field of collaborative online writing. A reason that explains this fact is that these tools enable students to manage the whole writing process from negotiation, construction of the text, revising and editing until the final product is realized ( $\mathrm{Li}, 2018)$. Furthermore, Web 2.0 tools, thanks to their collaborative essence, provide learners more chances to communicate and collaboratively write in the target language beyond time limitations of classrooms (Storch, 2012).

In their research, Zhou et al., (2012) have studied the effectiveness of Google Docs in an outside-class collaborative writing activity. The comparison between the experiment and control group has indicated that most students were not familiar with Google Docs before the study, the tool altered the means by which students communicated while writing collaboratively, $93 \%$ of students reported that Google Docs was a useful tool for group work, and half of the students stated they would like to use the tool in the future projects. However, the study indicated that Google Docs had no effect on students' paper grades. Another study conducted about Google Docs has demonstrated that students in the Google Docs group had significantly higher mean scores in writing than those worked in groups face-to-face. Moreover, students in Google Docs group reported positive attitudes toward collaborative writing activity, high collaboration in their groups, and ease of use (Suwantarathip \& Wichadee, 2014).

As for the use of blogs, a study conducted over a four-week period has pointed out that interactive nature of weblogs established a valid peer review culture as a major part of collaborative writing. Besides, students had positive attitudes towards weblogs and wanted to carry out similar tasks in the future English classes. Another vital skill students have gained is critical thinking and the ability to judge the feedback received from peers. As the feedback was provided by peers rather than instructors, this skill required students to make good judgments on which feedback to accept or discard (Grami, 2012). Another study conducted by Aydın and Yildız (2014) examined the use of wikis in collaborative writing projects in foreign language classrooms. The qualitative and quantitative data have demonstrated that the accuracy in grammar structures was $94 \%$. The students also reported positive experiences using wikis in foreign language writing, and they believed that there was an improvement in their writing performance. Besides, there have been observed more peer-corrections than self-corrections in wiki pages. 


\section{Learners' attitudes in CSCL}

With the increase in computer-supported learning (CSL), one of the most common fallacies has been to believe that achievement in the learning process mostly relies on technology and its effectiveness, thereby ignoring the whole system of learning environment including key constructs such as learners. That's why, with the introduction of CSL and CSCL, the research has mainly focused on the efficiency and effectiveness of the learning environment and technological tools used in this process (Zhou et al., 2012). However, without looking into learners and the affective factors impacting their views of these learning environments, the effectiveness and efficiency of these cannot be understood fully. Masgoret and Gardner (2003) state that learners' attitude toward the learning situation is one of the key variables for learning achievement, since learners cannot be separated from their perceptions, attitudes, views and emotions. Dörnyei (1994) also emphasizes the importance of learner and classroom-related factors and learners' views of these factors in his motivation studies, which proves that the studies looking into the attitude and perceptions of learners in CSCL process are quite critical. In a study by Storch (2005), it has been revealed that university students who chose to do a writing task collaboratively actually completed the task more competently compared to the ones choosing to study individually. Storch (2005) explains that collaborative work helps learners gather more ideas and get immediate feedback from their peers, a crucial part of the collaborative learning process. Another study investigating university students' perceptions of online collaborative writing demonstrates that most students saw the task co-operative instead of collaborative, and did not see online collaborative writing as an opportunity to create shared knowledge as a community, which reflects the critical guide role a teacher could play in the process (Limbu \& Markauskaite, 2015). Chen and Yu (2019) also examine learners' attitudes toward collaborative writing in a longitudinal study and find that attitudes may actually show changes in time and these changes may affect group interaction and learning opportunities positively or negatively. As these studies show, in order to understand the expectations of learners and to make better instructional choices as teachers, there is a need for more research on the affective factors affecting CSCL processes.

\section{Disaster Studies in Higher Education using The Community of Inquiry Framework}

The CoI framework has three presences, each of them intersects and informs the others to support the overall educational experience, namely, cognitive, social and teaching presence (Hilliard \& Stewart, 2019). In contrast, information systems students may acquire and apply knowledge and skills in relation to systems risk and recovery (Mendonca et al., 2019). As disasters present "wicked" problems that cannot be resolved from a single 
perspective, cognitive presence will need to support students to learn how to work in cross disciplinary teams and to understand how their specialist discipline knowledge contributes to solving transdisciplinary problems (Madrigano et al., 2017). In such contexts the CoI must also address students' need to attain "soft skills" and provide opportunities to reflect and discuss theory and practice in communication, situational awareness, coordination, decision making, negotiation, leadership, team building and stress management (Brooks et al., 2018).

During disasters, lives often depend on team cohesion, communication, coordination and cooperation (Hayes, 2015) and social presence underpins cohesive and collaborative interactions (Rourke et al., 1999). Whereas cognitive presence addresses student acquisition of hard and soft skills, social presence provides an open, trusting and lively environment to support students to develop the self-confidence to acquire them (Li, 2015). Social presence provides cohesion through establishment of not only socio-emotional presence and personal relationships but through intellectual focus, open and purposeful communication and respect. Students should feel safe to express their perspectives and views, to agree and disagree with others and yet still focus on a common goal (Hadwin et al., 2018).

This study aims to investigate EFL learners' attitudes toward online collaborative writing. With the use of the online collaborative writing tool, Padriseup, learners studying at a preparatory school at a state university have experienced online collaborative writing. With the attitude scale, we address the following research questions:

- What are students' attitudes towards using an online collaborative writing tool in pandemic EFL classes?

- What are students' experiences with using an online collaborative writing tool in pandemic EFL classes?

\section{Methodology}

\section{Research Design}

This small-scale mixed-method study, which investigates OCW with Padriseup to be able to answer the two research questions mentioned above and was conducted using an attitudinal survey along with two open-ended questions provided at the end of the online survey. In this descriptive study, a cross-sectional survey design was used. According to Creswell and Plano Clark (2011), mixed methods research focuses on gathering, analysing, and combining both quantitative and qualitative data in a single research or series of studies to gain a more in-depth understanding of research questions. 


\section{Setting}

The study took place at a state university during the fall semester of 2020-2021 academic year. Education was carried out fully online due to the pandemic. In the School of Foreign Languages, a progressive system is applied, and there are three main levels such as A1, A2, and B1. At the beginning of the fall term, students first take the proficiency exam prepared by the Testing office of the school, and if they take 70, they are exempt from studying at the prep school. Upon failing, they are distributed to their levels according to the result of the placement exam prepared by the Testing Office.

\section{Participants}

The participants were students studying English at a Preparatory Department of a State University in Turkey. In order to conduct the study, a convenience sampling method was used. The total number of participants in the study was 30 (23 females and 7 males) from various departments ranging from Biology to Logistics, who consented to take part in the study. The majority of the participants $(\mathrm{N}=19)$ attended online classes from Istanbul and stated that they used the internet more than six hours a day. The participants were elementary (A1:11) and pre-intermediate (A2:19) levels, which was determined by a placement test produced by the Testing Unit of the School of Foreign Languages. Finally, the participants' ages ranged between 18 and 22.

\section{Data Collection Tool}

The survey that was used to elicit participants' attitudes starts with questions regarding demographic information of the participants. As for the Online Cooperative Learning Attitude Scale (OCLAS), an online Likert scale attitudinal survey, prepared by Korkmaz (2012) was implemented in this quantitative study. The survey is comprised of 17 items with choices ranging from strongly agree to strongly disagree. Korkmaz (2012) has concluded that the Online Cooperative Learning Attitude Scale (OCLAS) has been proven to be a valid and reliable scale, and it can be utilized to determine students' attitudes towards online cooperative learning. The scale's factor and whole reliability analyses were calculated by using Cronbach's Alpha, which are as follows: Positive Attitude .899, Negative Attitude .822, and Total reliability .904 (Korkmaz, 2012). As for the qualitative data, in the last section of the survey, open-ended questions regarding the students' attitudes toward the tool have been added to gather in-depth insights.

\section{Data Collection Procedure}

Firstly, it is important to note that writing lessons of each class are four hours on the same day per week. Prior to the study, the teachers of each class gave a brief and to-the-point training session on Padriseup, also the participants were provided with a set of detailed criteria regarding the grading of their task on Padriseup. 
The procedure illustrated in the table below was followed for four weeks. As a warm-up activity, brainstorming and pair discussion were carried out. Afterwards, the participants were randomly divided into groups of 3 to 5 to work collaboratively on a writing task and they were provided with writing prompts and a link to Padriseup. After completing the task as shown in Figure 1, which was writing a well-organized paragraph of an essay, the teacher and students had a whole class discussion as a post-activity. This procedure was implemented throughout the four consecutive weeks. At the end of the process, participants were asked to reflect on their online collaborative writing experience with an online Likert scale attitudinal survey prepared by Korkmaz (2012).

Table 1: $\quad$ Four-week Procedure of Writing Lessons Carried Out with Padriseup

\begin{tabular}{llll}
\hline Week & Warm-up & Task & Post-activity \\
\hline 1 & Brainstorming, & Students write introduction paragraph of & Whole class \\
& Pair discussion & an opinion essay & discussion \\
2 & Brainstorming, & Students write the 1st body paragraph of & Whole class \\
& Pair discussion & an opinion essay & discussion \\
3 & Brainstorming, & Students write the 2nd body paragraph of & Whole class \\
& Pair discussion & an opinion essay & discussion \\
4 & Brainstorming, & Students write the conclusion paragraph & Whole class \\
& Pair discussion & of an opinion essay & discussion \\
\hline
\end{tabular}

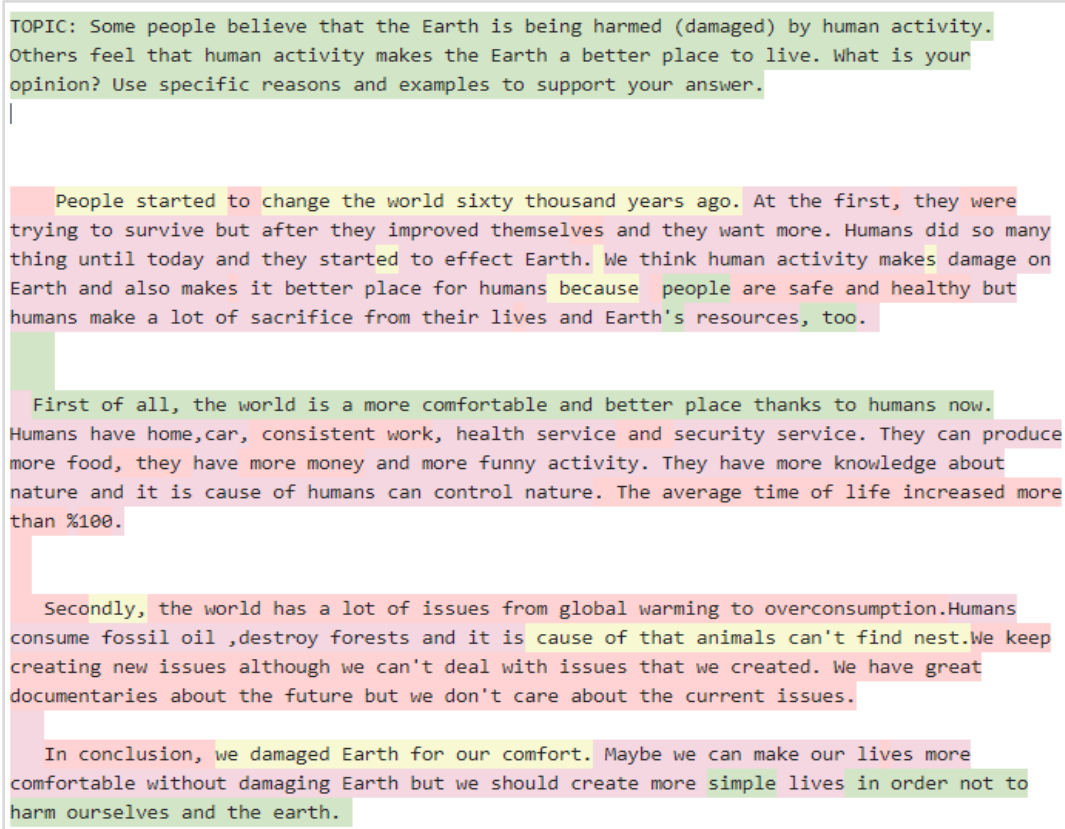

Figure 1 Student Essay Sample of Online Collaborative Writing with Padriseup

\section{Data Analysis}

In order to analyse the data obtained from the survey, Excel has been used to do descriptive analysis of the statistical data. The mean, mode and standard deviation of each item were calculated to better analyse the students' perceptions toward OCW. As for the analysis of the qualitative data obtained from the open-ended questions, content analysis has been 
conducted. This content analysis was done by taking the scale as a guide to decode the students' responses As Creswell (2009) has stated, to carry out the content analysis, students' responses were revised a couple of times and important key points from these were written and categorized to form codes. After forming the codes, categories and themes were created by taking the research questions into consideration. Therefore, the content analysis enabled us to create the relationships and meaning between the words and concepts so that they could be investigated, and inferences were made (Patton, 2002).

\section{Findings}

\section{Students' attitudes towards using an online collaborative writing tool}

To be able to answer the first research question in the study, a five-point Likert scale survey, with 17 items and the answers ranging from 1 - Strongly Disagree to 5 - Strongly Agree was administered. The survey results presented in Table 2 demonstrate the EFL students' perceptions regarding the use of an online collaborative writing tool in EFL classes. As a result of the responses to the survey, it was found out that the students in the study had a positive attitude towards using an online collaborative writing tool in EFL classes. When asked whether they enjoyed experiencing online collaborative learning via Padriseup, most of the students gave a positive answer with a mean score of 4.03. Furthermore, most of the students stated that being interactive with their group members had a positive influence on their motivation during online collaborative writing lessons and increased their creativity.

Table 2: $\quad$ The results of OCLAS Questionnaire

\begin{tabular}{|c|c|c|c|c|}
\hline & & Mean & Mode & $\begin{array}{l}\text { Standard } \\
\text { Deviation }\end{array}$ \\
\hline 1 & $\begin{array}{l}\text { I enjoy solving problems regarding the group project using } \\
\text { Padriseup with my group members. }\end{array}$ & 4.03 & 4.00 & 0.76 \\
\hline 2 & $\begin{array}{l}\text { Being interactive with the other group members using } \\
\text { Padriseup increases my motivation for learning. }\end{array}$ & 4.21 & 5.00 & 0.92 \\
\hline 3 & $\begin{array}{l}\text { I enjoy experiencing cooperative learning using Padriseup } \\
\text { with my group members. }\end{array}$ & 4.03 & 4.00 & 0.76 \\
\hline 4 & Online group activity increases our creativity. & 4.07 & 4.00 & 0.83 \\
\hline 5 & $\begin{array}{l}\text { I believe that the group can work on a document } \\
\text { effectively with the online cooperative learning } \\
\text { application. }\end{array}$ & 4.00 & 4.00 & 0.69 \\
\hline 6 & Padriseup improves my social skills. & 3.83 & 4.00 & 0.91 \\
\hline 7 & I enjoy helping others in Padriseup. & 4.10 & 4.00 & 0.80 \\
\hline 8 & Padriseup is very entertaining for me. & 3.66 & 4.00 & 0.88 \\
\hline 9 & Padriseup helps me feel better psychologically. & 3.55 & 4.00 & 0.85 \\
\hline 10 & More ideas come up because of Padriseup. & 4.10 & 4.00 & 0.84 \\
\hline 11 & $\begin{array}{l}\text { I think that I have had more successful results since I work } \\
\text { with a group in Padriseup. }\end{array}$ & 3.93 & 4.00 & 0.78 \\
\hline 12 & $\begin{array}{l}\text { Trying to teach something to my group members in } \\
\text { Padriseup does not make me tired. }\end{array}$ & 3.97 & 4.00 & 0.76 \\
\hline 13 & Padriseup makes sense to me. & 4.52 & 5.00 & 0.77 \\
\hline
\end{tabular}


14 I can develop my own ideas in Padriseup.

$4.52 \quad 5.00$

0.50

15 I like that people are depending on me in Padriseup.

$3.83 \quad 3.00$

0.95

16 I think that my interaction with my group members in

$4.45 \quad 5.00 \quad 1.04$

Padriseup will contribute to me.

$4.34 \quad 5.00 \quad 0.88$

Interestingly, $36 \%$ of the students responded that the use of Padriseup did not influence feeling psychologically better, which is reflected in Table 2 with a mean score of 3.55 as the lowest mean score compared to the others. It is also seen that the students found Padriseup mildly entertaining despite acknowledging its benefits.

The result of the survey suggests that most of the students in the study found Padriseup useful and see the potential for its use as an online collaborative writing tool. However, the standard deviation scores also show that a small number of students remain neutral or less interested in Padriseup, which might have resulted from various factors such as technology literacy and personality.

\section{Students' Experiences with Using an Online Collaborative Writing Tool}

To gain a closer sense of the variety in the students' responses towards the use of the online collaborative writing tool, responses to the open-ended questions in the survey were analysed through a meticulous content analysis.

Categories that emerged upon the content analysis are as follow: the categories on the pros are (a) sharing of ideas, (b) social learning, (c) product and process efficiency, (d) motivation; on the other hand, the categories emerged on the cons are (e) disagreements, (f) social loafing, (g) technology and software-related problems, (h) personality-related problems.

\section{Sharing of Ideas}

The category that dominates the responses about the advantages of the online collaborative tool is sharing ideas. Most students have reported that thanks to the tool, they have benefited from the exchange of ideas, which enabled them to learn about different perspectives, be exposed to a lot of ideas and create a better work at the end of the process.

The statements below support these findings:

"One of the advantages of the Padriseup is that a good work is created through a process of exchange of ideas."

"A lot of different ideas show up, which helps us to express the idea in our work in a much better way." 
Öz Dal, B., Güler, D., Tufan, E., \& Liman Kaban, A.

Using Padriseup as a Collaborative Writing Tool in Higher Education EFL Classes

Another related advantage is that students can pass their knowledge to one another. In the meantime, they can fuse their ideas together and create a better prepared work.

The statements below support these findings:

"The tool helps us work more productively and makes the exchange of knowledge easier."

"When working on the task, being able to consult for ideas by using the chat box has provided an important benefit to us."

\section{Social Learning}

Another pattern found in students' responses has indicated that the tool proved to be beneficial to learning. The responses show that students are aware of the fact that the tool has provided them a sense of learning together with an emphasis on peer-learning, peerfeedback and peer-scaffolding.

The statements below support these findings:

"As there are many minds involved, you can spot your mistakes faster."

"Because it is a collaborative task, everyone can teach something to everyone."

"Because there is a lot of team-work involved, we can help each other in terms of knowledge."

"The things that I love most are that I am in constant interaction with my peers, working on a collaborative task together. This improves our sociality and team-work skills.”

“We can spot each other's mistakes and correct them instantly."

Students' responses highlight that they associate the tool with a lot of interaction, more interactive lessons, communicating with peers throughout the process, and co-operative work.

The statements below support these findings:

"The things that I love most is that I am in constant interaction with my peers, working on a collaborative task together. This improves our sociality and team-work skills." 
Öz Dal, B., Güler, D., Tufan, E., \& Liman Kaban, A.

Using Padriseup as a Collaborative Writing Tool in Higher Education EFL Classes

\section{Product and Process Efficiency}

The findings have further indicated that students' responses included keywords such as increased efficiency and productivity both in terms of the product and process. Students mostly believe that they create a well-prepared product at the end. Also, some have reported an increased fulfilment felt towards the task and lesson.

The statements below support these findings:

"We achieve better productivity."

"The tool enables us to create a better-quality task as a team."

"Padriseup is a practical and useful tool."

"The tool increases the efficiency of the writing lessons."

"I believe that it increases the quality of the essay or the paragraph that we are writing."

\section{Motivation}

Analysing students' responses, it has been also found that students get more motivated and engaged throughout the process.

The statements below support these findings:

"It is always more fun to work with Padriseup."

"Together with friends, we get more motivated toward the task."

"Working as a group, producing new ideas together, and working collaboratively is very enjoyable, and Padriseup gives us this exactly."

\section{Disagreements}

As for the cons of the online collaborative writing tool, one of the most frequent responses was the communication-related issues. This includes conflicts among group members, conflicting ideas, not being able to reach a common ground, having disagreements, and the lack of conflict resolution.

The statements below support these findings:

"Sometimes there is a sentence that you want to write but cannot because this is a group work."

"We have disagreements sometimes." 
Öz Dal, B., Güler, D., Tufan, E., \& Liman Kaban, A.

Using Padriseup as a Collaborative Writing Tool in Higher Education EFL Classes

“Our ideas do not seem to meet on a common ground sometimes.”

\section{Social Loafing}

The findings show that a disadvantage of the online collaborative writing tool and the task is that inactive students might increase the burden of other group members.

The statements below support these findings:

"Some of our friends do not participate actively in the lesson, so the other group members have to complete the majority of the writing task."

"Because some peers do not simply write at all, the responsibility rests on the shoulders of the other group members."

\section{Technology and Software-Related Problems}

Certain comments found in the findings refer to the technical issues and interface of the software itself such as the lack of necessary add-in features in the software, the bad look of different colours, problems encountered when accessing from the mobile phone.

The statements below support these findings:

"As I cannot access the internet from my laptop, attending the lesson online from the mobile phone is disadvantageous."

"Some necessary add-in features are lacking in this tool, that's why it is limited in terms of accessibility. Also, different colours look bad sometimes." (Student here refers to the feature of the tool which enables each student to choose a colour code so that to whom a sentence belongs to is visible.)

\section{Personality-Related Problems}

Some participants have reported that the tool may not be appropriate for introverted students.

The statements below support these findings:

"The tool may not be useful for students who are unsocial."

\section{Discussion}

\section{Discussion of Students' Attitudes towards Using an Online Collaborative Writing Tool}

The results reveal that most students' experience with online collaborative writing via the web tool, Padriseup, was positive, and they conceived different benefits of it during the 
process. These results are in line with the research conducted by Storch (2005), whose earlier findings show that most students participating in her study regarding collaborative learning enjoyed the experience. Unlike traditional writing classes, where the teacher supports each student in their individual work, in OCW students take the responsibility of their own learning as well as their group members', being both the writer and the peer feedback provider (Chao \& Lo, 2011). As it was also revealed in the survey, students understood the value of collaboration in online writing classes, which made them more willing to participate in the tasks in Padriseup. However, due to its being a new concept, it was clear that the students needed more support in the process by the teacher to be able to make the most of the online collaborative writing, which supports deeper learning and coconstructing knowledge (Limbu \& Markauskaite, 2015).

\section{Discussion of Students' Experiences with Using an Online Collaborative Writing Tool}

The results have indicated that Padriseup has been beneficial in terms of sharing of ideas, social learning, product and process efficiency, interaction, motivation. In line with this study's findings regarding sharing of ideas, social learning, product and process efficiency and interaction, Limbu and Markauskaite (2015) have also pointed out in their qualitative study that OCW is regarded by students as a way to share work between participants to accomplish quality writing tasks, to blend powers together to produce a good product; as an activity which helps different ideas fuse and leads to a better understanding of content; and as a tool to gain new skills required for group work.

The rationale behind these findings lies in the fact that OCW is collaborative and socialconstructivist in essence. Writers who are in collaboration are required to communicate their ideas from the very beginning. They discuss, negotiate and add on each other's' contributions, therefore, expand not only their personal knowledge, but also contribute to collective meaning-making (Dye et al., 2010). In this sense, the findings are consistent with Zhu's (2012) study which revealed that online learning platforms have the potential to enhance students' collaborative learning practices and their knowledge construction thanks to group interaction.

Furthermore, our findings are in line with the social constructivist learning framework. As Vygotsky (1978) highlighted that collaborative learning is a must for helping students develop through his or her own zone of proximal development (ZPD), which is the gap between what the student could do alone and what one could realize when cooperating with others who are more skilled or experienced. Similarly, Wells (1999) stresses that there are three major characteristics that give scaffolding its particular character: the necessity dialogic of the dialogue where knowledge is co-constructed, the importance of the type of activity where the knowledge lies and the role of tools that foster knowledge building. 
Chao and Lo (2011) further states the importance of peer-scaffolding in collaborative learning and that collaborative learning is a strategy for teaching that offers opportunities for learners to be assisted by their peers; especially collaborative writing, through being exposed to various perspectives and ideas, can help decrease anxiety about experiencing a writer's block and task difficulty. As the participants in our study also indicated, online collaborative writing tools support social learning thanks to the extensive amount of interactions, exchange of novel ideas and peer-scaffolding practices as well as peerrevising, peer-feedback and peer-learning.

On the other hand, the categories that emerged on the cons are (a) disagreements, (b) social loafing, (c) software-related problems, (d) the duration, (e) personality-related problems. The findings of this study also resonate with the literature concerning the challenges in OCW. Problems with discussing the understanding of the task and sharing goals and standards for tasks might have a significant impact on regulation and task performance regardless of whether learners work on their own or collaboratively (Hadwin et al., 2018). Various studies indicate that disagreement is an inherent part of collaborative tasks (Mutwarasibo, 2013; Sharma, 2012). Mutwarasibo's (2013) research with undergraduate students in collaborative writing also revealed that profound disagreement among group members is likely to take place.

As the findings of this study have demonstrated, social loafing is another issue that has aroused during online collaborative writing processes. Hall and Buzwell (2012) reported that social loafing is one of the most important elements causing dissatisfaction among students in group projects; they tend to dislike collaborative work mostly because of the interpersonal dissension that might occur. According to the collective effort model, social loafing takes place when the team members are not able to see the value of the contribution that they make or the task itself and having quality communication helps the team members to articulate the contribution that they have made to the project (Karau \& Williams, 1993).

Online education has its own requirements that need to be taken into consideration to accomplish the objectives in terms of learning. As the findings of this study revealed, the lack of technological equipment or software-related issues can be barriers that hinder this aim. Similarly, the research conducted by Assareh and Bidokht (2010) in Shahid Rajaee University in Iran indicated having access to necessary technological equipment is an essential element for online learning. According to Capra (2011) if learners are not technologically equipped for online education, this may affect both the learners and the instructor in an adverse manner. 
Having a varying working pace is one of the challenges that participants of this study encountered during OCW. Barkley et al. (2005) posit that when working as a team, it is possible for some group members to work at varying speeds; some might dominate the team while others are likely to diverge from the topic of the discussion. In their study with undergraduate students on challenges in online collaboration, Hadwin et al. (2018) found out that a big number of students regarded time as the most noteworthy challenge that they experienced while working collaboratively.

Participants in the study indicated that OCL might not be suitable for introverted students. Jackson (2014) claims that introverts favour learning tasks in which they can work independently and individually; teamwork does not allocate the time they need for procession and reflection. Introverts are mainly characterized as introspective, so it creates a contrast with the spontaneous atmosphere of active learning classrooms (Condon \& Ruth-Sahd, 2013).

\section{Limitations of the study}

This study has some limitations that can be considered for future studies. The very first limitation of the study is the sample size which involved 30 participants in total. The study was conducted in two preparatory classes at a state university, yet some students could not be reached because of the fully online classes without attendance taken as a result of the pandemic.

Another limitation of the study is that there were two teachers involved in the process, which may affect students' attitudes towards the online collaborative writing tool. In order to increase the number of the participants in the study, the tool was used in two different classes with different teachers; however, the teachers tried to follow the same protocol in their lesson plans.

\section{Recommendation for future research}

This study offers many possibilities for future research. First of all, the interaction patterns of the participants in chat box were not analysed in this small-scale study. In the future research, these patterns can be investigated with their relation to students' achievement and/or perceptions. How much contribution was made by each student and its relation to their level of English was not within the scope of this research, which can be considered for future research. Also, a study focusing on the longitudinal effects of using an online collaborative writing tool could reveal more insight into the area of online collaborative learning. Besides, as the tool requires each student to assign a colour to himself/herself giving the researcher to assess the individual contribution, further studies can examine the amount of individual contribution and participation in relation to other variables such as knowledge growth, motivation and sense of belonging. 


\section{Conclusion}

As is clear, emergency distance education due to the pandemic has led to a higher number of attempts to incorporate OCL tools into teaching and learning. Specifically, collaborative online writing tools have been implemented in the EFL writing lessons more and more. In this regard, with the purpose of investigating the EFL students' attitudes toward an OCW tool, this mixed-method study concludes that quantitative and qualitative data analysis yielded the similar finding that the participants' attitudes towards the online collaborative writing tool were positive. The results of the questionnaire indicated that participants enjoyed using the OCW tool and reported higher levels motivation and interaction while using the tool. Similarly, the qualitative data demonstrated that the majority of students reported that advantages of the OCW tool such as social learning, motivation, interaction, sharing of ideas, product and process efficiency outweigh the disadvantages such as social loafing, disagreements, software and personality related problems. Therefore, the study might act as a valuable contributor to the literature of online collaborative learning in EFL classes.

\section{References}

Ananiadou, K., \& Claro, M. (2009). $21^{\text {st }}$ Century Skills and Competences for New Millennium Learners in OECD Countries. OECD Education Working Papers. http://dx.doi.org/10.1787/218525261154

Assareh, A., \& Hosseini Bidokht, M. (2011). Barriers to e-teaching and e-learning. Procedia Computer Science, 3, 791-795. http://doi: 10.1016/j.procs.2010.12.129

Aydin, Z., \& Yildiz, S. (2014). Using Wikis to Promote Collaborative EFL Writing. Language Learning \& Technology, 18(1), 160-180.

Barkley, E. F., Cross, K. P., \& Major, C. H. (2005). Collaborative learning techniques: A handbook for College Faculty. Danvers: Jossey-Bass.

Capra, T. (2011). Online education: promise and problems. Merlot Journal of Online Learning and Teaching, 7, 288-293.

Chao, Y. C. J., \& Lo, H. C. (2011). Students' perceptions of Wiki-based collaborative writing for learners of English as a foreign language. Interactive Learning Environments, 19(4), 395-411. doi:10.1080/10494820903298662

Chen, W., \& Yu, S. (2019). A longitudinal case study of changes in students' attitudes, participation, and learning in collaborative writing. System, 82, 83-96. doi:10.1016/j.system.2019.03.005 
Condon, M., \& Ruth-Sahd, L. (2013). Responding to introverted and shy students: Best practice guidelines for educators and advisors. Open Journal of Nursing, 3(07), 503515. https://doi.org/10.4236/ojn.2013.37069

Cresswell, J. W. (2009). Research design: Qualitative and quantitative and mixed methods approaches $\left(3^{\text {rd }}\right.$ ed.). Thousand Oaks, CA: Sage Publications.

Creswell, J. W., \& Plano Clark, V. L. (2011). Designing and conducting mixed methods research $\left(2^{\text {nd }}\right.$ ed.). Thousand Oaks, CA: Sage Publications, Inc.

Dillenbourg, P. (1999). What do you mean by collaborative learning? In P. Dillenbourg (Ed.), Collaborative learning: Cognitive and Computational Approaches (pp. 1-19). Oxford: Elsevier. hal-00190240

Dörnyei, Z. (1994). Motivation and Motivating in the Foreign Language Classroom. The Modern Language Journal, 78(3), 273-284. doi:10.2307/330107

Dye, V., Herrington, M., Hughes, J., Kendall, A., Lacey, C., \& Smith, R. (2010). Collaborative writing and dis-continuing professional development: challenging the rituals and rules of the education game? Professional Development in Education, 36(1-2), 289-306.

Grami, G. (2012). Online Collaborative Writing for ESL Learners Using Blogs and Feedback Checklists. English Language Teaching, 5(10), 43-48.

Hall, D., \& Buzwell, S. (2012). The problem of free-riding in group projects: Looking beyond social loafing as reason for non-contribution. Active Learning in Higher Education, 14(1), 37-49. https://doi.org/10.1177/1469787412467123

Hadwin, A. F., Bakhtiar, A., \& Miller, M. (2018). Challenges in online collaboration: effects of scripting shared task perceptions. International Journal of ComputerSupported Collaborative Learning, 13, 301-329. https://doi.org/10.1007/s11412-0189279-9

Harasim, L. (2017). Connectivism as an Online Learning Theory. Learning Theory and Online Technologies, 80-104. doi:10.4324/9781315716831-6

Harasim, L. (2000). Shift happens: Online education as a new paradigm in learning. The Internet and Higher Education, 3(1-2), 41-61. doi:10.1016/s1096-7516(00)00032-4

Jackson, S. (2014). Student reflections on multimodal course content delivery. Reference Services Review, 42(3), 467-483. https://doi.org/10.1108/rsr-05-2014-0011

Johnson, D. W., \& Johnson, R. T. (1991). Collaboration and Cognition. In A. L. Costa (Ed.), Developing Minds: A Resource Book for Teaching (Revised ed., Vol. 1, pp. 298301). Alexandria, Virginia: Association for Supervision and Curriculum Development. 
Karau, S. J., \& Williams, K. D. (1993). Social loafing: A meta-analytic review and theoretical integration. Journal of Personality and Social Psychology, 65(4), 681-706. https://doi.org/10.1037/0022-3514.65.4.681

Korkmaz, Ö. (2012). A validity and reliability study of the Online Cooperative Learning Attitude Scale (OCLAS). Computers \& Education, 59, 1162-1169. doi:10.1016/j.compedu.2012.05.021

Lexico. (n.d.). Collaboration. Lexico.com dictionary. Retrieved October 02, 2021, from https://www.lexico.com/definition/collaboration

Li, M. (2018). Computer-mediated collaborative writing in L2 contexts: an analysis of empirical research. Computer Assisted Language Learning, 31(8), 882-904.

Limbu, L., \& Markauskaite, L. (2015). How do learners experience joint writing: University students' conceptions of online collaborative writing tasks and environments? Computers \& Education, 82, 393-408. doi:10.1016/j.compedu.2014.11.024.

Masgoret, A. M., \& Gardner, R. C. (2003). Attitudes, motivation, and second language learning: A meta-analysis of studies conducted by Gardner and Associates. Language Learning, 53(1), 123-163. https://doi.org/10.1111/1467-9922.00212

Mutwarasibo, F. (2013). Promoting university students' collaborative learning through instructor-guided writing groups. International Journal of Higher Education, 2(3). http://dx.doi.org/10.5430/ijhe.v2n3p1

Messer, J. (2020). Turning it inside out: Independent reading in the middle school classroom. Illinois Reading Council Journal, 48(2), 3-18.

Pace, C., Pettit, S. K., \& Barker, K. S. (2020). Best practices in middle level quaranteaching: Strategies, tips and resources amidst COVID-19. Becoming: Journal of the Georgia Association for Middle Level Education, 31(1), 2.

Patton, M. Q. (2002). Qualitative research and evaluation methods. Thousand Oaks, CA: Sage Publications.

Reeves, T. C., Herrington, J., \& Oliver, R. (2004). A development research agenda for online collaborative learning. Educational Technology Research and Development, 52(4), 53-65. doi:10.1007/bf02504718

Sharma, B. K. (2012). Conceding in disagreements during small group interactions in academic writing class. Classroom Discourse, 3(1), 4-28. https://doi.org/10.1080/19463014.2012.666024

Storch, N. (2005). Collaborative writing: Product, process, and students' reflections. Journal of Second Language Writing, 14(3), 153-173. 
Storch, N. (2012). Collaborative writing as a site for L2 learning in face-to-face and online modes. CALICO Monograph Series, 10, 113-129.

Suwantarathip, O., \& Wichadee, S. (2014). The Effects of Collaborative Writing Activity Using Google Docs on Students' Writing Abilities. TOJET: The Turkish Online Journal of Educational Technology, 13(2), 148-156.

Tocalli-Beller A. (2003). Cognitive conflict, disagreement and repetition in collaborative groups: affective and social dimensions from an insider's perspective. The Canadian Modern Language Review, 60(2), 143-71.

Toquero, C. M. (2020). Challenges and opportunities for higher education amid the COVID-19 pandemic: The Philippine context. Pedagogical Research, 5(4).

Trochim, W. M., \& Donnelly, J. P. (2001). Research methods knowledge base (Vol. 2). Cincinnati, OH: Atomic Dog Publishing.

Wells, G. (1999). Dialogic inquiry: Towards a sociocultural practice and theory of education. New York: Cambridge University Press.

Vygotsky, L. S. (1978). Mind in society. Cambridge, Massachusetts: Harvard University Press.

Zhou, W., Simpson, E., \& Domizi, D. (2012). Google Docs in an out-of-class collaborative writing activity. International Journal of Teaching and Learning in Higher Education, 24(3), 359-375.

Zhu, C. (2012). Student Satisfaction, Performance, and Knowledge Construction in Online Collaborative Learning. Educational Technology \& Society, 15(1), 127-136. 